\title{
Papers
}

\section{Prospective randomised controlled trial of an infection screening programme to reduce the rate of preterm delivery}

Herbert Kiss, Ljubomir Petricevic, Peter Husslein

\begin{abstract}
Objective To evaluate whether a screening strategy in pregnancy lowers the rate of preterm delivery in a general population of pregnant women.

Design Multicentre, prospective, randomised controlled trial. Setting Non-hospital based antenatal clinics.

Participants 4429 pregnant women presenting for their routine prenatal visits early in the second trimester were screened by Gram stain for asymptomatic vaginal infection. In the intervention group, the women's obstetricians received the test results and women received standard treatment and follow up for any detected infection. In the control group, the results of the vaginal smears were not revealed to the caregivers.

Main outcome measures The primary outcome variable was preterm delivery at less than 37 weeks. Secondary outcome variables were preterm delivery at less than 37 weeks combined with different birth weight categories equal to or below $2500 \mathrm{~g}$ and the rate of late miscarriage.

Results Outcome data were available for 2058 women in the intervention group and 2097 women in the control group. In the intervention group, the number of preterm births was significantly lower than in the control group $(3.0 \% v 5.3 \%, 95 \%$ confidence interval 1.2 to $3.6 ; \mathrm{P}=0.0001$ ). Preterm births were also significantly reduced in lower weight categories at less than 37 weeks and $\leq 2500 \mathrm{~g}$. Eight late miscarriages occurred in the intervention group and 15 in the control group.

Conclusion Integrating a simple infection screening programme into routine antenatal care leads to a significant reduction in preterm births and reduces the rate of late miscarriage in a general population of pregnant women.
\end{abstract}

\section{Introduction}

Preterm delivery (birth before 37 completed weeks of gestation) is the leading cause of neonatal morbidity and mortality. In recent years the birth weight of premature babies has been found to be an important determinant of outcome, such that preterm birth is no longer defined solely by gestational age but also in terms of a birth weight below $2500 \mathrm{~g}$. The main focus has been on preterm infants with a birth weight below $2000 \mathrm{~g}$, who bear the greatest burden of morbidity and mortality. The costs of neonatal care for infants born at less than 33 weeks of gestation (birth weight below $2000 \mathrm{~g}$ ) rise exponentially as gestational age decreases and rise further with birth weights below $1000 \mathrm{~g}$.

Advances in neonatal practice have improved the chances of survival for preterm infants with a very low birth weight. ${ }^{2}$ However, low birthweight infants are still at a higher risk of neurodevelopmental morbidity than preterm infants with a higher birth weight and, as a group, incur notable social and healthcare costs, ${ }^{3-5}$ related not only to acute neonatal intensive care but also to the long term sequelae arising from preterm birth.

Studies have estimated the high direct costs incurred after the initial hospitalisation in the first year of a healthy infant with a birth weight below $2000 \mathrm{~g}$. The lifetime costs per preterm birth have been estimated at $€ 766339$ (£511 614; \$941 640), ${ }^{4}$ with physical or mental disability resulting in incremental increases in the cost of healthcare services.

Although the causes of preterm delivery are complex and manifold, a prior history of late miscarriage or preterm delivery remains the most predictive risk factor. ${ }^{6}$ Compelling evidence now exists that infection is not only associated with preterm delivery but that it is a causative factor. ${ }^{78}$ Vaginal infections, particularly bacterial vaginosis, have consistently been shown in many longitudinal population studies to be associated with late miscarriage and preterm delivery. ${ }^{9-13}$ A review of the current literature shows conflicting data on the benefits of routine screening for bacterial vaginosis, ${ }^{14}{ }^{15}$ particularly in populations at low risk. ${ }^{16}$ Studies of interventions to prevent preterm labour as well as studies aimed at arresting the progression of established preterm labour have largely shown a consistent lack of efficacy. ${ }^{17}$

Uniform recommendations on effective screening methods to prevent preterm delivery are still lacking. We therefore evaluated a simple antenatal programme to prevent preterm births. This programme entailed general screening for and standardised treatment of the vaginal infections with the highest prevalence, regardless of whether the infection is clearly associated with preterm delivery or whether no link has been established, as is the case in candidiasis. ${ }^{18}$ The goal of the programme was to reduce the rate of preterm births and late miscarriages.

\section{Methods}

Between January 2001 and October 2002, 25 non-hospital based obstetricians in the Vienna area enrolled pregnant women presenting for their routine prenatal visits between $15+0$ (15 weeks plus 0 days) and 19+6 weeks (19 weeks plus 6 days) of gestation. Patients' obstetricians determined gestational age on the basis of the date of a woman's last menstrual period and confirmed this by ultrasound before 19 weeks of gestation. The obstetricians included women without subjective complaints (contractions, vaginal bleeding, or symptoms suggestive of vaginal infection) into the study after obtaining individual informed consent. We excluded women erroneously included-those who did not fulfil the inclusion criteria in terms of week of gestation or clinical symptoms of vaginal infection, or those with multiple pregnancies. 
In addition to the routine antenatal examinations the women's obstetricians assessed vaginal smears, transferred to a microscopic slide. To diagnose bacterial vaginosis we Gram stained all preparations in a central laboratory and used the scoring system proposed by Nugent et al for our evaluation. ${ }^{19}$ Evaluations also included screening for the presence of Candida species and Trichomonas vaginalis on Gram stain. The study protocol differentiated between bacterial vaginosis (Nugent grade 3 ), vaginal candidiasis (spores and hyphae), infection with Tvaginalis, or combinations of any of the three.

\section{Randomisation}

After the obstetricians had enrolled the women into the study, the case report forms and smear samples went to the central laboratory, where they were randomly assigned to the intervention group or the control group. Randomisation was performed according to a computer generated randomisation list. In the intervention group, obstetricians provided vaginal smear results. All obstetricians and women in the intervention group received their smear results. In the control group, obstetricians and participating women remained blinded to the test results.

\section{Treatment}

Women in the intervention group who were found to have a pathological vaginal flora or another microscopically diagnosed infection received standardised treatment within seven to 10 days of diagnosis. Bacterial vaginosis (Nugent grade 3) was treated for six days with clindamycin $2 \%$ vaginal cream. Persistent or recurrent disease was treated with oral clindamycin $300 \mathrm{mg}$ twice daily for seven days. Candidiasis (spores and hyphae) was treated with local clotrimazole $0.1 \mathrm{~g}$ for six days. Trichomoniasis was treated with local metronidazole $500 \mathrm{mg}$ for seven days and included treatment of the partner. Women's obstetricians took follow up vaginal smears at the time of the next routine antenatal visit, between $24+0$ and $27+6$ weeks of gestation. Treatment for persistent or recurrent candidiasis or trichomoniasis was repeated. We used a telephone recall system to check compliance with treatment of the women in the intervention group. In the control group we concealed the test results from the women and their doctors so that they did not influence the women's standard antenatal care programme.

\section{Evaluation of results}

The primary outcome variable was the rate of spontaneous preterm delivery (delivery at less than 37 weeks). Secondary outcome variables were spontaneous preterm delivery at less than 37 weeks in combination with birth weights equal to or below $2500 \mathrm{~g}, 2000 \mathrm{~g}$, and $1500 \mathrm{~g}$, respectively. We defined spontaneous preterm delivery as either vaginal or caesarean delivery due to preterm labour or preterm premature rupture of membranes. We analysed separately all medically indicated (iatrogenic) preterm deliveries due to pre-eclampsia or eclampsia, HELLP (haemolysis, elevated liver, low platelet) syndrome, placenta praevia, abruption of the placenta, or malformation of the fetus. Moreover, we evaluated the rates of miscarriage between 16-22 and 20-24 weeks of pregnancy and intrauterine death and assessed the distribution and prevalence of various forms of vaginal infection and the duration of sick leave and hospitalisation.

\section{Statistical methods}

The primary outcome measure was spontaneous preterm delivery. We used the $\chi^{2}$ test to test the hypothesis that a smaller rate of spontaneous preterm delivery is expected in the intervention group than the control group. Our significance level was $\mathrm{P}<0.05$

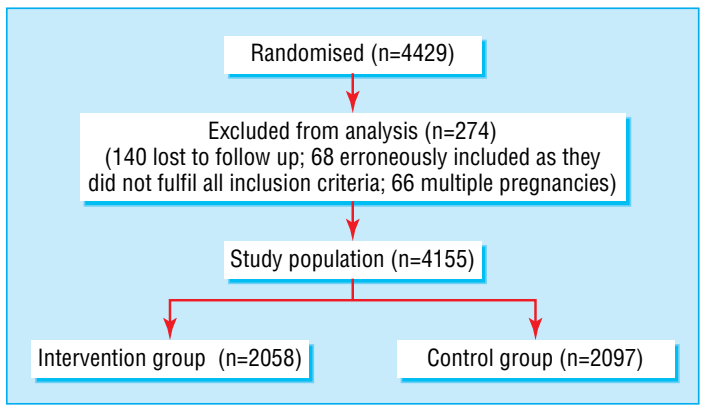

Fig 1 Flow of participants through the trial

(two tailed). We based our sample size estimation on an estimated rate of spontaneous preterm delivery of $7 \%$ and considered a reduction to (at least) 5\% clinically important. On the basis of these assumptions and a power of $80 \%$ we considered a sample size of 2000 per group adequate. We tested the secondary outcome measures (spontaneous preterm delivery at less than 37 weeks in combination with birth weights equal to or below $2500 \mathrm{~g}, 2000 \mathrm{~g}$, and $1500 \mathrm{~g}$, respectively) in the same way. We used SPSS, version 11.0, for all statistical calculations.

\section{Results}

Between January 2001 and October 2002 we considered a total of 4429 pregnant women for enrolment into the study. Of these, 4155 women completed the screening programme (fig 1). The mean age of the patients was 28.9 (SD 5.6) years. Mean gestational age at the time we obtained the secretions was 17 (SD 1.6) weeks. Table 1 shows the number of primiparous and multiparous women and the number of previous preterm births in the screened population. About 98\% (4080) of women were of white ethnic origin. Almost $80 \%$ of examined smears did not show any evidence of infection. The remaining $20 \%$ showed an abnormal vaginal flora, with no differences between the intervention and control groups. Table 2 summarises the distribution of the various forms of infection in the screened patient population.

Outcome data were available from 2058 women in the intervention group and 2097 women in the control group. The difference in the rates of spontaneous preterm birth between the intervention group and the control group reached significance $(3.0 \%, v 5.3 \%, 95 \%$ confidence interval $1.2 \%$ to $3.6 \% ; \mathrm{P}=0.0001)$. The number of preterm infants with a birth weight equal to or below $2500 \mathrm{~g}$ was significantly lower in the intervention group than in the control group $(1.7 \% v 3.5 \%, 0.9$ to $2.8 ; \mathrm{P}=0.0002)$. The number of spontaneous preterm births in the lower weight categories was 50\% lower (table 3, fig 2) than in the control group. The rate of late miscarriage was also reduced by $50 \%$, whereas the number of intrauterine deaths was comparable between the two groups (table 4). Table 5 provides an overview of

Table 1 Obstetric history of study population. Values are numbers (percentages) of pregnant women

\begin{tabular}{lll} 
& Intervention group & Control group \\
\hline Primiparous & $986(47.9)$ & $1002(47.8)$ \\
\hline Multiparous & $1072(51.9)$ & $1095(52.0)$ \\
\hline Total & $2058(49.5)$ & $2097(50.5)$ \\
\hline $\begin{array}{l}\text { Multiparous with a history of } \\
\text { preterm delivery: }\end{array}$ & \\
\hline Week 33+0 to 36+6 & $47(2.2)$ & $45(2.1)$ \\
\hline Week 23+0 to 32+6 & $22(1.1)$ & $24(1.1)$ \\
\hline
\end{tabular}


Table 2 Distribution of normal and abnormal vaginal flora in the screened patient population. Values are numbers (percentages) of pregnant women

\begin{tabular}{lcc} 
Microscopic finding & Intervention group & Control group \\
\hline Normal flora & $1611(78.3)$ & $1656(79.0)$ \\
\hline Abnormal flora: & $447(21.7)$ & $441(21.0)$ \\
\hline Bacterial vaginosis & $151(7.3)$ & $146(7.0)$ \\
\hline Bacterial vaginosis+Candida & $24(1.2)$ & $32(1.5)$ \\
\hline $\begin{array}{l}\text { Bacterial vaginosis+Candida }+ \\
\text { Trichomonas vaginalis }\end{array}$ & $0(0.0)$ & $1(0.0)$ \\
\hline Bacterial vaginosis+T vaginalis & $2(0.1)$ & 0 \\
\hline Candida & $270(13.1)$ & $259(12.4)$ \\
\hline$T$ vaginalis & 0 & $3(0.1)$ \\
\hline
\end{tabular}

the subgroup analysis of the women diagnosed as having an infection at the initial examination and the number of preterm births by intervention and control group.

Among the 447 women who had a follow up Gram stain after the first course of treatment, asymptomatic vaginal infection was still present in 123 (27.5\%); 44 had bacterial vaginosis, 8 had bacterial vaginosis and candidiasis, 70 had candidiasis, and 1 had trichomoniasis. We treated all women again according to the study protocol. None of the women reported adverse events during the treatment period. Adverse events would not have been a reason for exclusion from or discontinuation of treatment, because the study focus was to compare a screened with a non-screened population. The groups did not differ significantly with regard to passage of meconium, necrotising enterocolitis, neonatal sepsis, and neonatal death during hospitalisation. Among preterm infants with a birth weight below $1500 \mathrm{~g}$ no case of necrotising enterocolitis during the stay at the neonatal intensive care unit was documented in the neonatology (NICU) records (data not shown).

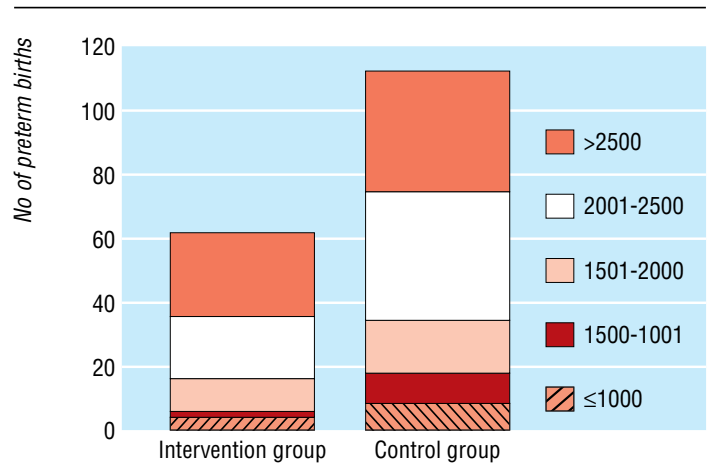

Fig 2 Number of spontaneous preterm deliveries in the intervention and control groups

\section{Discussion}

Incorporating a simple screening and treatment programme for subclinical vaginal infections into routine prenatal care early in the second trimester reduces the rate of spontaneous preterm deliveries by $50 \%$ in all weight categories. This reduction is likely to be associated with massive reductions in the direct and indirect costs associated with preterm delivery.

Preterm delivery represents a major public health concern. Rates are on the rise; preterm infants cause substantial emotional and economic costs to their families and communities and have a disproportionate impact on the use of health services. ${ }^{20}$ Various working groups have argued consistently that a reduction in preterm births is most likely to be achieved when specific prevention programmes can be provided to pregnant women. $^{91321}$

The literature provides evidence that the long term financial burden imposed by preterm birth on families and social services far exceeds the initial costs of treatment. For example, $40 \%$ of preterm children with a birth weight below $2500 \mathrm{~g}$ will exhibit behavioural problems later in life, including attention deficit disorders, delinquency, social problems, and anxiety problems. ${ }^{5}$

\section{Comparison with other studies}

In a report on a non-randomised trial McGregor et al advocated that screening for common infections of the genital tract should be offered to pregnant women to reduce preterm births. ${ }^{9}$ To date, however, screening for vaginal infection has not become a routine part of antenatal care, mostly because there have been no studies to confirm that screening and treating pregnant women at low risk for bacterial vaginosis significantly reduces the rate of preterm birth, particularly with regard to low birthweight infants. ${ }^{14}{ }^{15}$ Screening for candidiasis is not recommended because a large study has shown that moderate to heavy Candida colonisation is not associated with preterm birth. ${ }^{18}$ Yet candidiasis is common during pregnancy and is the infection most commonly associated with subjective complaints, which is why we included it in our screening programme for common infections of the genital tract. Even though we also screened for Tvaginalis, this pathogen was rare in our population and is therefore unlikely to affect the results of our study. In contrast to most previous studies investigating the role of screening for bacterial vaginosis only, we assessed the benefits of a simple screening programme for asymptomatic vaginal infection in a general population of pregnant women. Our study also shows a notable reduction in preterm delivery for birth weights below $2500 \mathrm{~g}$.

Ugwumadu et al showed recently that screening for and treating asymptomatic abnormal vaginal flora and bacterial vaginosis early in the second trimester reduces the rate of preterm birth in a general obstetric population. ${ }^{22}$ Lamont et al showed that topical treatment with clindamycin vaginal cream, also applied early in the second trimester, reduces the incidence

Table 3 Cumulative distribution of preterm births at less than 37 weeks by birth weight and gestational age in the intervention ( $\mathrm{n}=2058)$ versus the control group $(n=2097)$

\begin{tabular}{|c|c|c|c|c|}
\hline & No in intervention group (\%) & No in control group (\%) & Difference $(95 \% \mathrm{CI})$ & $P$ value ( $\chi^{2}$ test) \\
\hline $\begin{array}{l}\text { Total No of preterm births ( }<37 \text { weeks) by } \\
\text { birth weight: }\end{array}$ & $61(3.0)$ & $112(5.3)$ & 2.4 (1.2 to 3.6$)$ & 0.0001 \\
\hline$\leq 2500 \mathrm{~g}$ & $35(1.7)$ & $74(3.5)$ & $1.8(0.9$ to 2.8$)$ & 0.0002 \\
\hline$\leq 2000 \mathrm{~g}$ & $15(0.7)$ & $33(1.6)$ & $0.8(0.2$ to 1.5$)$ & 0.011 \\
\hline$\leq 1500 \mathrm{~g}$ & $5(0.2)$ & $17(0.8)$ & $0.6(0.1$ to 1.0$)$ & 0.012 \\
\hline$\leq 1000 \mathrm{~g}$ & $3(0.1)$ & $7(0.3)$ & $0.2(-0.1$ to 0.5$)$ & 0.211 \\
\hline \multicolumn{5}{|l|}{ Gestational age: } \\
\hline Week $33+0$ to $36+6$ & $48(2.3)$ & $88(4.2)$ & 1.9 (0.8 to 2.9) & 0.0007 \\
\hline Week $23+0$ to $32+6$ & $13(0.6)$ & $24(1.1)$ & $0.5(-0.1$ to 1.1$)$ & 0.079 \\
\hline
\end{tabular}




\begin{tabular}{|c|c|c|c|c|}
\hline Type of birth & No in intervention group (\%) & No in control group(\%) & Difference $(95 \% \mathrm{CI})$ & $P$ value $\left(\chi^{2}\right.$ test $)$ \\
\hline Birth at term & $1955(95.0)$ & $1947(92.8)$ & $-2.1 \quad(-3.6$ to -0.7$)$ & 0.004 \\
\hline $\begin{array}{l}\text { Spontaneous preterm birth ( }<37 \text { weeks } \\
\text { of gestation) }\end{array}$ & $61(3.0)$ & $112(5.3)$ & 2.4 (1.2 to 3.6$)$ & 0.0001 \\
\hline $\begin{array}{l}\text { Medically indicated (iatrogenic) } \\
\text { preterm birth* }\end{array}$ & $24(1.2)$ & $14(0.7)$ & $-0.5(-1.1$ to 0.1$)$ & 0.091 \\
\hline Intrauterine death & $10(0.5)$ & $9(0.4)$ & $-0.1(-0.5$ to 0.4$)$ & 0.786 \\
\hline Miscarriage $†$ & $8(0.4)$ & $15(0.7)$ & $0.3(-0.1$ to 0.8$)$ & 0.156 \\
\hline Total & $2058(100.0)$ & $2097(100.0)$ & & \\
\hline \multicolumn{5}{|l|}{$\begin{array}{l}\text { Medically indicated (iatrogenic) } \\
\text { preterm birth due to*: }\end{array}$} \\
\hline Pre-eclampsia & $9(0.4)$ & $8(0.4)$ & & \\
\hline $\begin{array}{l}\text { HELLP (haemolysis, elevated liver, } \\
\text { low platelet) syndrome }\end{array}$ & $4(0.2)$ & $1(0.0)$ & & \\
\hline $\begin{array}{l}\text { Severe intrauterine growth } \\
\text { retardation }\end{array}$ & $3(0.1)$ & 0 & & \\
\hline Fetal malformation & $2(0.1)$ & $2(0.1)$ & & \\
\hline $\begin{array}{l}\text { Placental abnormalities (placenta } \\
\text { praevia, placental abruption) }\end{array}$ & $4(0.2)$ & $3(0.1)$ & & \\
\hline $\begin{array}{l}\text { Non-obstetrical causes (appendicitis, } \\
\text { peritonitis) }\end{array}$ & $2(0.1)$ & 0 & & \\
\hline \multicolumn{5}{|l|}{ Miscarriage by weeks of gestation†: } \\
\hline 16-20 weeks & $4(0.2)$ & $11(0.5)$ & & \\
\hline$>20$ weeks & $4(0.2)$ & $4(0.2)$ & & \\
\hline
\end{tabular}

*Medically indicated preterm birth, listing the different diagnoses for iatrogenic induced preterm births.

†Explains the two different groups.

of preterm birth, ${ }^{23}$ despite the reservations regarding topical treatment of bacterial vaginosis that were expressed by many authors. ${ }^{15}$ In contrast to these studies, we assessed a screening strategy for common infections of the genital tract. A subgroup analysis showed that treating asymptomatic vaginal infections reduces the rate of preterm birth. However, because the sample sizes are too small, this subgroup analysis must be interpreted with caution.

\section{Surprising finding}

What may be considered an unusual trait of our study design is that we also screened for and treated Candida colonisation, even

Table 5 Subgroup analysis: women with abnormal vaginal flora (see also table 2) and with spontaneous preterm delivery at less than 37 weeks of gestation. Values are numbers of patients unless otherwise indicated

\begin{tabular}{|c|c|c|}
\hline Subgroup and diagnosis & Intervention group & Control group \\
\hline \multicolumn{3}{|l|}{ Births at term: } \\
\hline Bacterial vaginosis & 144 & 135 \\
\hline Bacterial vaginosis+Candida & 23 & 30 \\
\hline $\begin{array}{l}\text { Bacterial } \\
\text { vaginosis+Trichomonas } \\
\text { vaginalis }\end{array}$ & 2 & 0 \\
\hline $\begin{array}{l}\text { Bacterial vaginosis }+ \text { Candida }+T \\
\text { vaginalis }\end{array}$ & 0 & 1 \\
\hline Candida & 258 & 238 \\
\hline$T$ vaginalis & 0 & 2 \\
\hline Total No $(\%)$ of births at term & $427(95.5)$ & $406(92.1)$ \\
\hline \multicolumn{3}{|l|}{ Spontaneous preterm births: } \\
\hline Bacterial vaginosis & 5 & 8 \\
\hline Bacterial vaginosis+Candida & 1 & 2 \\
\hline Candida & 7 & 20 \\
\hline$T$ vaginalis & 0 & 1 \\
\hline $\begin{array}{l}\text { Total No (\%) of spontaneous } \\
\text { preterm births }\end{array}$ & $13(2.9)$ & $31(7.0)$ \\
\hline $\begin{array}{l}\text { Medically indicated (iatrogenic) } \\
\text { preterm birth }\end{array}$ & $1(0.2)$ & 0 \\
\hline Intrauterine death & $5(1.1)$ & $1(0.2)$ \\
\hline Miscarriage & $1(0.2)$ & $3(0.7)$ \\
\hline Total & $447(100)$ & $441(100)$ \\
\hline
\end{tabular}

though current research shows that candidiasis is not associated with preterm birth. ${ }^{18}$ However, the purpose of our study was to screen, as part of the routine prenatal care programme, for the vaginal infections with the highest prevalence in our population of patients. Even though the subjective burden of fungal infection in pregnancy is difficult to determine objectively, we considered it not ethically feasible to inform a woman that her vaginal secretions exhibited heavy Candida colonisation with spores and hyphae but that she was not going to receive treatment. Against this backdrop, our finding that a reduction in preterm birth was found, not only in patients diagnosed with and treated for bacterial vaginosis but also in patients with candidiasis, was rather surprising. On the basis of evidence from the published literature, it is unclear whether treatment of Candida colonisation has an impact on pregnancy outcome. In our study the subgroup analysis is not amenable to further interpretation, because we designed the study to assess a general screening approach for any of the common vaginal infections.

\section{Possible reason for good results}

The clear reduction in the rate of preterm births seen in our study, particularly in the lower weight categories, was surprising, not only in view of the data previously published in the literature ${ }^{14-16}$ but also against the backdrop of the publications mentioned above. ${ }^{22}{ }^{23}$ Our good results may be due to the fact that women were included in a screening programme. In the intervention group, women without vaginal infection were informed that their vaginal flora was normal. On the other hand, doctors may well have provided a different level of care to women in the study group in whom an infection had been identified. In view of the known association between bacterial vaginosis and preterm birth, obstetricians consider women with bacterial vaginosis or persistent or recurrent vaginosis as patients at high risk and handle them with particular care.

\section{Subtitle}

We compared the rates of preterm births in a screened and treated population with those in a non-screened population, and we therefore made a particular point of using objective diagnos- 


\section{What is already known on this topic}

Preterm delivery is the most important cause of perinatal mortality and morbidity

A clear association exists between vaginal infection and preterm delivery

\section{What this study adds}

Integrating a simple infection screening programme into routine antenatal care can reduce the rate of preterm births by $50 \%$

Screening and treatment of asymptomatic infections should be performed early in the second trimester (week 17)

tic criteria. Objective evidence of infection can be obtained only on the basis of a standardised method of interpreting vaginal smears, and Gram stain interpretation according to Nugent is the most objective method. ${ }^{19}$ This is confirmed by results reported in the literature. ${ }^{19}{ }^{22}{ }^{23}$ In their investigation on the value of symptoms and signs in the diagnosis of vaginal infection, Schaaf et al found that about $50 \%$ of women with clinically diagnosed vaginal infection lacked a microbiologic diagnosis in a standardised follow up examination, ${ }^{24}$ which shows that the success of routine screening for infection depends in large part on the use of a standardised diagnostic method.

Any preterm prevention programme must be tailored to meet the specific needs of each care delivery setting, taking into account not only the prevalence of infection but also differences in the extent of coverage of antenatal care programmes by different health systems. Considerable variations exist in the worldwide prevalence of lower reproductive tract infections. In our population of pregnant women, some $20 \%$ had microscopic evidence of infection or abnormal colonisation. The prevalence of Candida colonisation (spores and hyphae) was high (14\%), whereas the prevalence of bacterial vaginosis alone or in combination with other infections was low $(8.5 \%)$, compared with prevalence rates reported for other countries, which range between $10 \%$ and $40 \%{ }^{11}$

\section{Outlook}

We believe that our results are generalisable to other countries with comparable populations and patterns of antenatal healthcare delivery. Routine screening for asymptomatic vaginal infection and the ensuing decrease of $50 \%$ in the rate of preterm births will probably translate into a reduction of more than $50 \%$ in the costs of prematurity.

Acknowledgments: We thank the medical-technical assistants of the Microbiology Laboratory of the Department of Obstetrics and Gynaecology for their commitment throughout the study, and H Leitich, A Ugwumadu for constructive criticism. We also thank A Millendorfer and G Niernberger for their statistical analysis and constructive comments.

Contributors: HK contributed to design, analysis, and interpretation of results, and writing of the report and is the study guarantor. LP managed the collection and documentation of data and contributed to the statistical analyses, and $\mathrm{PH}$ contributed to the original design of the study. The following, non-hospital based obstetricians from the Vienna area enrolled pregnant women presenting for the routine antenatal visits into the study: $\mathrm{P}$ Bruck, A Colloredo-Mannsfeld, M Elnekheli, W Eppel, A Fink, R Fitz, W Forster, H Fröhlich-Dolinar, N Ghazanfari-Sawadkuhi, B Haghi, D Jelincic, E-M Joura, E Küffer, W Markel, W Miechowiecki, P Mohammadi, I Müller-
Klingspor, K M Radner, R Reichel, M Stany, G Stegner, M Stiglbauer jun, S Stino, N Vavra, B Wiesenthal.

Funding: Fund "Healthy Austria" ("Fonds Gesundes Österreich") grant PNr. 205/V/12 and Federal Ministry of Education, Science, and Culture grant GZ 70.069/1-Pr4/2000.

Competing interests: None declared.

Ethical approval: Ethics committee of the University of Vienna Medical School, Austria.

1 St John EB, Nelson KG, Cliver SP, Bishnio RR, Goldenberg RL. Cost of neonatal care according to gestational age at birth and survival status. Am J Obstet Gynecol 2000;182:170-5.

2 Ahner R, Kohlhauser C, Bikas D, Rabl M, Langer M, Pollak A, et al. Grenzen der fetalen Lebensfähigkeit und Konsequenzen für das geburtshilfliche Management. Geburtsh Frauenheilk 2000;60:20-5.

3 Xu B, Rantakallio P, Jarvelin MR. Mortality and hospitalizations of 24-year-old members of the low-birthweight cohort in northern Finland. Epidemiology 1998;9:662-5

4 Petrou S, Sach T, Davidson L. The long term costs of preterm birth and low birth weight: results of a systematic review. Child Care Health Dev 2001;27:97-115.

5 Elgen I, Sommerfelt K, Markestad T. Population based, controlled study of behavioural problems and psychiatric disorders in low birthweight children at 11 years of age. Arch Dis Child Fetal National Ed 2002; 87: 128-32.

6 Mercer BM, Goldenberg RL, Moawad AH, Meis PJ, Iams JD, Das AF, et al. The preterm prediction study: effect of gestational age and cause of preterm birth on subsequent obstetric outcome. Am J Obstet Gynecol 1999;181:1216-21.

7 Gibbs RS, Romero R, Hillier SL, Eschenbach DA, Sweet RL. A review of premature birth and subclinical infection. Am J Obstet Gynecol 1992;166:1515-28.

8 Hillier SL, Martius J, Krohn M, Kiviat N, Holmes KK, Eschenbach DA. A case-control study of chorioamnionic infection and histologic chorioamnionitis in prematurity. $N$ Engl J Med 1988;319:972-8.

9 McGregor JA, French JI, Parker R, Draper D, Patterson E, Jones W, et al. Prevention of premature birth by screening and treatment for common genital tract infection: Results of a prospective controlled evaluation. Am J Obstet Gynecol 1995;173:157-67.

10 Gravett MG, Nelson HP, DeRouen T, Critchlow C, Eschenbach DA, Holmes KK. Independent associations of bacterial vaginosis and chlamydia trachomatis infection with adverse pregnancy outcome. JAMA 1986;256:1899-903.

11 McGregor JA, French JI. Bacterial vaginosis in pregnancy. Obstet Gynecol Survey 2000;55(suppl):1-19.

12 Hay PE, Lamont RF, Taylor-Robinson D, Morgan DJ, Ison C, Pearson J. Abnormal bacterial colonisation of the genital tract and subsequent preterm delivery and late miscarriage. $B M J$ 1994;308:295-8

13 Meis PJ, Goldenberg RL, Mercer B, Moawad A, Das A, McNellis D, et al. The preterm prediction study: significance of vaginal infections. Am J Obstet Gynecol $1995 ; 173: 1231-5$.

14 Brocklehurst $\mathrm{P}$, Hannah M, McDonald $\mathrm{H}$. Interventions for treating bacterial vaginosis in pregnancy. Cochrane Database Syst Rev 2000;(2):CD000262.

15 Leitich H, Brunbauer M, Bodner-Adler B, Kaider A, Egarter C, Husslein P. Antibiotic treatment of bacterial vaginosis in pregnancy: a meta-analysis. Am J Obstet Gynecol 2003; $188: 752-8$

16 Carey JC, Klebanoff MA, Hauth JC, Hillier SL, Thom EA, Ernest JM, et al. Metronidazole to prevent preterm delivery in pregnant women with asymptomatic bacterial vagizole to prevent preterm delivery in 10 .
nosis. N Engl J Med 2000;342:534-40.

17 Goldenberg RL. The management of preterm labor. Obstet Gynecol 2002;100:1020-37.

17 Goldenberg RL. The management of preterm labor. Obstet Gynecol 2002;100:1020-37. Cotch MF, Hillier SL, Gibbs RS, Eschenbach DA. Epidemiology and outcomes associ-
ated with moderate to heavy Candida colonization during pregnancy. Am J Obstet Gynecol 1998;178:374-80.

19 Nugent RP, Krohn MA, Hillier SL. Reliability of diagnosing bacterial vaginosis is improved by a standardized method of Gram stain interpretation. J Clin Microbiol 1991;29:297-301.

20 Mattison DR, Damus K, Fiore E, Petrini J, Alter C. Preterm delivery: a public health perspective. Paediatr Perinatal Epidemiol 2001;15(suppl 2): -16.

21 Hoyme UB, Möller U, Saling E. Ergebnisse und mögliche Konsequenzen der Thüringer Frühgeburtenvermeidungsaktion 2000. Geburtsh Frauenheilk 2002;62:25763.

22 Ugwumadu A, Manyonda I, Ried F, Hay P. Effect of early oral clindamycin on late miscarriage and preterm delivery in asymptomatic women with abnormal vaginal flora and bacterial vaginosis: a randomised controlled trial. Lancet 2003;361:983-8.

23 Lamont RF, Dunchan SLB, Mandal D, Basset P. Intravaginal clindamycin to reduce preterm birth in women with abnormal genital tract flora. Obstet Gynecol 2003;101:51622.

24 Schaaf VM, Perez-Stable EJ, Borchardt K. The limited value of symptoms and signs in the diagnosis of vaginal infections. Arch Intern Med 1990;150:1929-33.

$$
\text { (Accepted } 23 \text { June 2004) }
$$

doi 10.1136/bmj.38169.519653.EB

Department of Obstetrics and Gynaecology, University of Vienna Medical School, Währinger Gürtel 18-20, A-1090 Vienna, Austria

Herbert Kiss associate professor of obstetrics and gynaecology

Ljubomir Petricevic research fellow

Peter Husslein professor of obstetrics and gynaecology

Correspondence to: H Kiss herbert.kiss@akh-wien.ac.at 